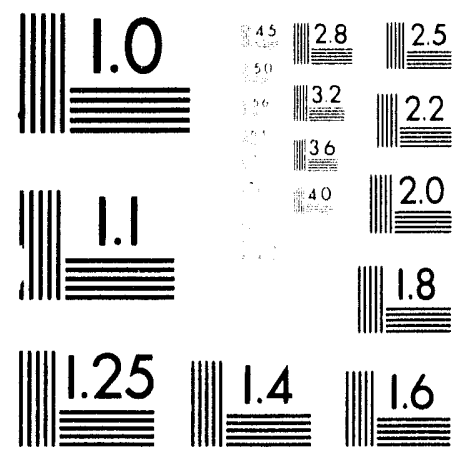



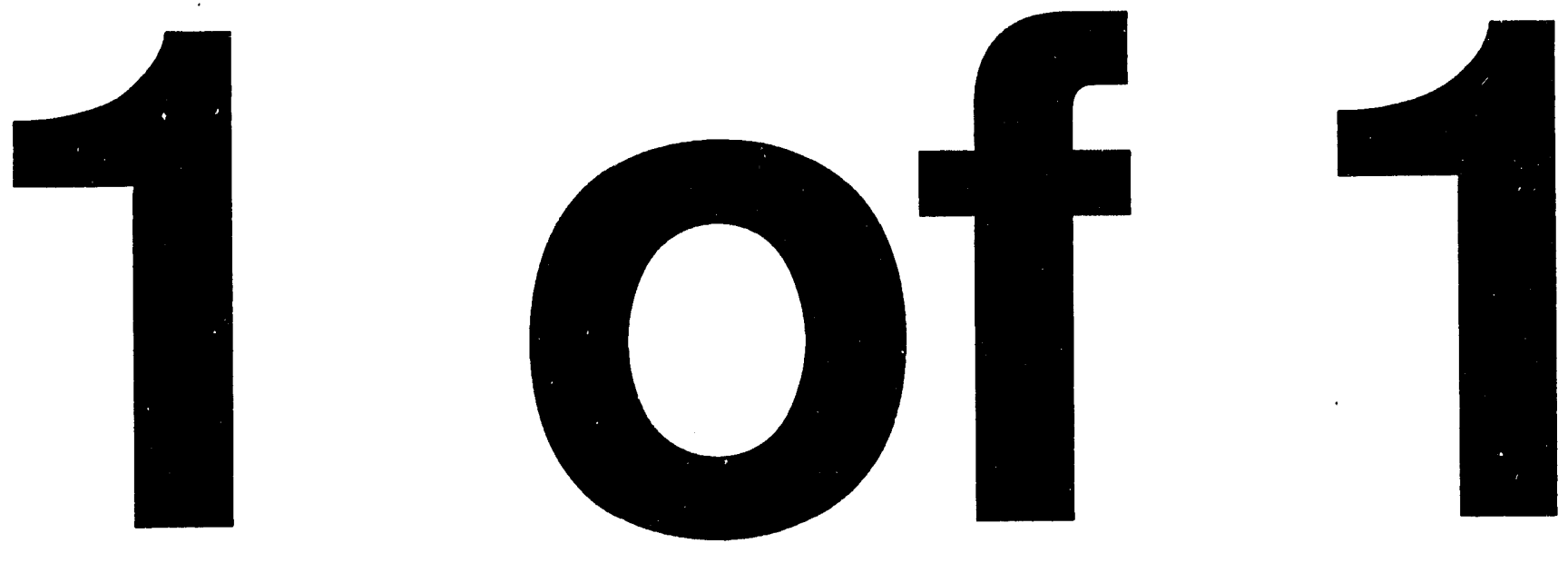


\section{DISCLAIMER}

This report was prepared as an account of wotk sponsored by an agency of the United States Govermment. Neither the United States Govermment nor any agency thereof, nor any of their employees, makes any warranty, express or implied, or assumes any legal liability or responsibility for the accuracy, completeness, or usefulness of any information, apparatus, product, or process disclused, or represents that its use would not infringe privately owned rights. Reference herein to any specific commercial product, process, or service by trade name, trademark, manufacturer, or otherwise does not necessarily constitute or imply its endorsement, recommendation, or favoring by the United States Government or any agency thereof. The views and opinions of authors expressed herein do not necessarily state or reflect those of the United States Government or any agency thereof.

This report has been reproduced directly from the best available copy.

Available to DOE and DOE contractors from the Office of Scientific and Technical Information, 175 Oak Ridge Turnpike, Oak Ridge, TN 37831; prices available at $(615) 576-8401$.

Available to the public from the National Technical Information Service, U.S. Department of Commerce, 5285 Port Royal Road, Springfield, VA 22161; phone orders accepted at (703) 487-4650. 


\title{
CE IGCC Repowering Project Hot Gas Clean Up System
}

\author{
Topical Report
}

Work Performed Under Contract No.: DE-FC21-90MC26308

\author{
For \\ U.S. Department of Energy \\ Office of Fossil Energy \\ Morgantown Energy Technology Center \\ P.O. Box 880 \\ Morgantown, West Virginia 26507-0880 \\ By \\ Combustion Engineering. Inc \\ ABB Combustion Engineering Systems \\ 1000 Prospect Hill Road \\ Windsor, Connecticut 06095
}

September 1993

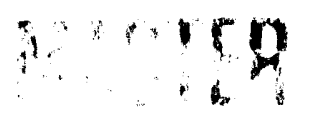




\section{TOPICAL REPORT}

\section{HOT GAS CLEAN UP SYSTEM}

\section{SUMMARY}

With sponsorship from the Department of Energy (DOE), and the state of Illinois, Combustion Engineering, Inc. is currently developing a design for a $60 \mathrm{Mw}$ IGCC (Integrated Coal Gasification Combined Cycle) for City Water, Light \& Power (CWL\&P) in Springfield, Illinois. In addition, to DOE and the state of Illinois, Combustion Engineering, Inc. and CWL\&P are contributing to the project. In order to obtain a high thermal efficiency, a hot gas cleanup system has been incorporated for product gas clean up. The cleanup system currently incorporated in the system design is one that is being developed by General Electric Environmental Services, Inc. (GEESI). This is a moving bed process which includes the regeneration of the sorbent material.

Testing of the system is currently underway in GEESI's piiot plant in Schenectady, New York. The hot gas clean up system will use a moving-bed of zinc titanate as an absorbent material to capture gaseous sulfur species in the gas. The cleanup system will be required to operate in a range of $850-1150^{\circ} \mathrm{F}\left(454-621^{\circ} \mathrm{C}\right)$ and under a pressure of 20 atmospheres.

Results of the tests indicate that overall sulfur efficiency exceeds $95 \%$, the zinc titanate can be regenerated, and produces an $\mathrm{SO}_{2}$-rich tail gas suitable for conversion to sulfuric acid, elemental sulfur or disposable waste.

\section{INTRODUCTION}

Combustion Engineering, Inc. (CE) received approval from the federal Department of Energy (DOE) to develop a design for a low BTU gasifier that will have a high efficiency. In order to accomplish this, the gas clean up incorporates a hot gas desulfurization system currently being developed by GEESI. The system incorporates a moving-bed of zinc titanate to remove the sulfur and particulate from the gas stream. Data from GEESI's pilot test unit will be used to design a full-scale system at CWL\&P.

The CWL\&P hot gas cleanup system will use the full fuel gas flow at 20 atmospheres with a temperature that will range from 850 to $1150{ }^{\circ} \mathrm{F}\left(454-621^{\circ} \mathrm{C}\right)$. Fuel gas derived from coal contains sulfur, mainly in the form of $\mathrm{H}_{2} \mathrm{~S}$ with some COS. Mixed metal oxide components can react with the gaseous sulfur species forming regenerable metal sulfides under reducing conditions in the temperature range of 850 to $1150{ }^{\circ} \mathrm{F}\left(454-621^{\circ} \mathrm{C}\right)$. GEESI's patented moving bed process includes the regeneration of a sorbent material. 
At CWL\&P, the scaled up version of the GEEESI system is expected to achieve:

- Greater than 99 percent overall sulfur removal at full gasifier operating conditions.

- A reduction of concentrated particulate to levels acceptable for gas turbine and NSPS (New Source Performance Standards) requirements.

- Production of an $\mathrm{SO}_{2}$-rich tail gas suitable for conversion to sulfuric acid, elemental sulfur or disposable waste.

\section{SYSTEM DESCRIPTION}

Figure 1 shows the process configuration and the general arrangement for the moving bed hot gas cleanup system as it is integrated into the CE gasifier unit for CWL\&P. The gasifier and hot gas cleanup system are located in a new building located to the west of the existing turbine building.

The low Btu gas (L.BG) generated by CE's entrained flow gasification system has a typical gas composition of:

$\begin{array}{lr}\mathrm{CO} & 23.2 \% \text { by volume } \\ \mathrm{CO} 2 & 4.2 \% \\ \mathrm{H} 2 & 8.7 \% \\ \mathrm{H} 2 \mathrm{O} & 4.6 \% \\ \mathrm{~N} 2, \mathrm{AR} & 58.8 \% \\ \mathrm{H} 2 \mathrm{~S}, \mathrm{COS} & 0.5 \%\end{array}$

Prior to the LBG entering the hot gas cleanup system, particulate in the gas is removed via a cyclone and bay filter at the operating conditions of $1000 \mathrm{deg}$. F. and a nominal pressure range of 256 to $294 \mathrm{psig}$. The cyclone separates a nominal $65 \%$ of the particulate from the gas. The gas and remaining particulate discharge from the cyclone to two parallel particulate filters each sized to handle $50 \%$ of the gas and particulate load. The particulate filters resemble conventional cylindrical bag filter modules used for gas filtration. The filtration media has not been selected at this time but will be one of the following: Nextel, a woven ceramic, sintered inconel metal, or ceramic candles. This type of filtration system is incorporated up stream of the hot gas cleanup system for the following reasons. First, over half of the particulate is less than 20 microns in size. Cyclones alone are not capable of removing the required amount of particulate of this size. For the hot gas cleanup system to operate properly, only a trace of particulate can be in the gas stream. Second, the hot gas cleanup system is designed to operate at temperatures over 800 deg. F. and above. Conventional filtration media are not capable of operation at these temperatures. 


\section{Hot Gas Desulfurization Process Description}

\section{Basic Process Concept}

The basis for the GEESI hot gas desulfurization system is a regenerable mixed metal oxide $\mathrm{H}_{2} \mathrm{~S}$ sorbent technology. Zinc titanate will be used as the sorbent materials in the CE/City of Springfield Project. Syngas derived from the medium-high sulfur coals contains sulfur compounds primarily in the form of $\mathrm{H}_{2} \mathrm{~S}$ and COS. These sulfur compounds react with mixed-metal oxides in the reducing environment of the absorber to form metal sulfides and water according to the following equation.

$$
\mathrm{MO}+\mathrm{H}_{2} \mathrm{~S} \rightarrow \mathrm{MS}+\mathrm{H}_{2} \mathrm{O}
$$

The metal sulfides can be regenerated in a reaction with oxygen to re-form metal oxides and produce sulfur dioxide according to the following equation. The sulfur dioxide produced in the regeneration "off gas" can be utilized as feed stock for an acid plant to produce sulfuric acid.

$$
\mathrm{MS}+1.5 \mathrm{O}_{2} \rightarrow \mathrm{MO}+\mathrm{SO}_{2}
$$

The HGCU system consists of the following major subsystems.

1) Fines Removal System

2) Halogen Removal System

3) Absorber

4) Regenerator

5) Regeneration "Off Gas" Recycle System

6) Solids Transport System

\section{Fines Removal System}

The hot gas clean up (HGCU) system uses several different types of particulate removal devices, including high efficiency cyclones (2), vibrating screen fines separators (2), and a baghouse. In addition, the absorber will act as a granular bed filter to take out some of the larger size fines in the syngas stream.

A high efficiency cyclone will be used to remove Sodium Bicarbonate introduced upstream and the reacted by-products.

Two $50 \%$ capacity vibrating screen fines separators are used to filter fines coming from the regenerator system. Dust loading from the vibrating screen fines separators will be removed in a small pulse jet baghouse. 
The final particulate removal device in the HGCU system is a high efficiency cyclone.

\section{Halogen Removal System}

The GEESI HGCU system will employ Sodium Bicarbonate Injection, upstream of the absorber, in order to remove the halogen species, according to the following equation.

$$
1.5 \mathrm{NaHCO}_{3}+\mathrm{HCl} \rightarrow \mathrm{NaCl}+\mathrm{H}_{2} \mathrm{O}+\mathrm{CO}_{2}+\text { (Excess } \mathrm{NaHCO}_{3} \text { ) }
$$

The Sodium Bicarbonate will be injected upstream of the second high efficiency cyclone, with up to 1.5 times the stoichiometric ratio and residence time of at least $200 \mathrm{msec}$, using a rotary feeder as a metering device.

\section{Absorber}

Following primary particulate and halogen removal, syngas from the airblown CE gasifier enters the absorber and flows upward, countercurrent to a periodically moving bed of zinc titanate pellets. The sulfur compounds in the syngas react with the sorbent pellets to form metal sulfides as described above. In addition to the sulfided sorbent, certain particulate maiter will be trapped in the absorber and transported to the regenerator system.

\section{Regenerator}

The sorbent regeneration step is a highly exothermic process requiring careful temperature control. Temperatures above $1800^{\circ} \mathrm{F}$ will cause sintering of the sorbent material, reducing its sulfur removal capacity. Temperatures below $1200^{\circ} \mathrm{F}$ will result in sulfate formation and loss of sulfur removal performance. The regeneration process is broken down into two stages. The upper stage, where the oxidation process takes place; and the lower stage where the sorbent is cooled and the $\mathrm{SO}_{2}$ rich "off gas" purged. in order to control the oxygen concentration, and hence the temperature, a large fraction of the $\mathrm{SO}_{2}$ rich "off gas" is recycled back to the regenerator for use as a diluent to the oxidant. The oxidant is extraction air from the turbine compressor.

\section{Regeneration "Off Gas" Recycle System}

The Regeneration "Off Gas" Recycle System has three primary functions. The first function is to deliver the $\mathrm{SO}_{2}$ rich "off gas" to the sulfuric acid plant for conversion to sulfuric acid. The second function is to provide diluent for the oxidation process in the regenerator. The third function is to use the heat generated by the syngas sulfur to produce steam. 


\section{Solid Transport System}

Sorbent is transported to a bin located at the top of the HGCU tower by two vibrating feeders supplied by two skip hoists, each having $50 \%$ capacity. Sorbent moves down through the absorber, regenerator, and a system of lockhoppers, by gravity, in a sequential manner.

\section{Control System Overview}

The control system used in the plant will be a Distributed Control System (DCS). Design of the DCS will be by others based on GEESI specification, such as, digital/analog logic diagrams, 1/O list, graphics design, and written descriptions.

The following sections describe the required instrumentation and controls for each of the major subsystems outlined above.

\section{Fines Removal}

\section{$\underline{\text { Cyclones }}$}

For each of the two high efficiency cyclones in the HGCU system, inlet pressure, outlet pressure, and differential pressure across the cyclone will be measured.

The primary and secondary cyclone lockhopper will have a high level switch in order to signal a full lockhopper and resulting dump sequence, and also a low level switch to signal an empty lockhopper. The secondary cyclone lockhopper will have a pressure transmitter on the vent line transmitting an analog input to the DCS to indicate pressure inside the lockhopper, as well as means to monitor solids level, internal temperature, and skin temperature.

\section{Vibrating Screen Fines Separators}

The overall sorbent movement timing sequence defines the sequence in which the vibrating screen fines separators are turned off and on. The DCS will provide start/stop signals to the vibrating screen separator motor. Definition of "fines" and "coarse" sorbent will result from test operating experiences and can be altered by replacing screens.

\section{Baghouse}

The baghouse used in conjunction with the Vibrating Screen Fines Separator will be a purchased item and will be sized to handle dust loadings from both 
separators at one time. The baghouse will include instrumentation, valves, and control system. Plant air will be supplied to the baghouse for operation. The DCS will provide start/stop signals to the baghouse PLC control system.

\section{Halogen Removal}

Sodium bicarbonate will be metered into the syngas stream, upstream of the secondary cyclone, based on syngas chloride concentration, with nitrogen as the carrier gas. The sodium bicarbonate will be stored in a storage silo that will be supplied from a truck filling station located at grade level. The storage silo will use a small baghouse to suppress dust during the loading process. The sodium bicarbonate will be fed from the storage silo to a mill classifier system (if size reduction is required) by a screw feeder, then pneumatically conveyed to a baghouse into a collector bin. The collector bin feeds a charge lockhopper which in turn feeds a run lockhopper. The sodium bicarbonate will be metered into the syngas stream through a rotary feeder, whose feed rate is based on syngas chloride concentration, with nitrogen as the carrier gas.

The storage silo will use level detectors to display silo level at the truck fill station to prevent overfill of the silo. The bag filter on top of the storage silo will be back pulsed with nitrogen during the fill process. The mill/classifier final product size will be controlled by adjusting air flow through the blower. The final product size will be a function of the residence time required to complete the halogen-sodium bicarbonate reaction. The baghouse collector bin, used to feed the charge lockhopper, will use level detectors to start/stop the screw feeder, mill classifier and blower through the DCS. The charge lockhopper and run lockhopper will be mounted on load cells to monitor the level and sodium bicarbonate discharge rate. A chloride concentration monitor, located at the HGCU system inlet, will be used to adjust the rotary feeder feed rate.

\section{Absorber}

One of the most important control functions in the entire HGCU system is the sequential transter of sorbent through the absorber to the regenerator and back again. This sequence can be initiated on one of the two conditions, time (manually move bed after a predetermined time interval) or combination of outlet $\mathrm{H}_{2} \mathrm{~S}$ concentration and pressure drop across the absorber bed (automatic control). The entire sorbent transfer sequence is based on a 2 hour time interval between sorbent bed movements.

The sorbent lockhoppers and bin play a critical role in this sorbent transfer sequence. Each lockhopper will have a pressure transmitter on the vent line transmitting an analog input to the DCS to indicate pressure inside the lockhopper. Each lockhopper and bin will have provision for monitoring sorbent level, internal temperature, and vessel shell temperature. 


\section{$\underline{\text { Regenerator }}$}

When the regenerator is operated in the "trickle flow" mode, the rotary feeder is energized enabling a continuous flow from the absorber outlet lockhopper, through the regenerator, and to the regenerator outlet lockhopper. The DCS will provide signals to start/stop the rotary feeder and to vary the rotary feeder's speed of rotation.

\section{Regeneration "off gas" Recycle System}

In addition to providing the correct amount of oxygen to the regenerator to maintain the regeneration process, temperature control in the regenerator is crucial to the success of the regeneration process. The temperature control of the upper regeneration stage is accomplished by using a control scheme that utilizes regenerator temperature and oxygen concentration as control parameters.

There are three modes of operation which occur in the following order: (1) Initial pre-heating of the bed, (2) Long duration start-up, (3) Steady state operation.

During the initial pre-heating mode, the partially sulfided bed is elevated to a temperature of approximately $900^{\circ} \mathrm{F}$ using electrically heated, recirculating, nitrogen gas. This mode of operation will use the start-up heater and the heat added by the compressor in order to obtain the desired bed temperature.

As a result of the long duration start-up mode, a steady state, high temperature profile will be obtained throughout the bed. The time constant of this mode of operation will be approximately 20-24 hours. In this mode of operation, the recycle flow will be set at the maximum recycle rate, and control will be accomplished with a high percentage of oxygen to the regenerator and scanning the internal bed temperatures assuring $\operatorname{Tmax}<1550^{\circ} \mathrm{F}$. Once a Tmax is reached, the air will be turned off. When all bed temperatures are below $1450^{\circ} \mathrm{F}$, the air will be turned on again. In this mode of operation, the "off gas" oxygen concentration is ignored and the air introduction is controlled in an on/off manner using temperature as the control parameter.

Once a steady state bed temperature profile is reached, the steady state mode of operation can be applied. In this mode of operation, the recycle rate is held constant, the bed temperatures will be scanned for Tmax and the air valve controlled on an on/off basis. A second mode of control can be added. The "off gas" oxygen concentration can be used as a PID control parameter for the air introduction valve(s). This mode of control can be described as outlet oxygen control with temperature override. 
The lower stage inlet will allow either air or nitrogen flow. Pilot plant operation and general consideration for sulfate formation make nitrogen the preferred gas. Air or a blend of air and nitrogen may be required, however, to provide the maximum $\mathrm{SO}_{2}$ concentration for the sulfuric acid plant.

The recycle loop pressure is maintained at a constant level by a pressure control valve.

\section{Solids Transport System}

The transport system sorbent movement sequence is a multi-step sequence within the overall sorbent transfer sequence to transfer the contents of the lower bin to the upper bin.

Normal operation is two trips per bucket for each sorbent transfer to the absorber.

Control signals are sent from the DCS in order to open/close valves, start/stop bucket hoists, and engage/disengage.

Each bucket will have a dedicated load cell to sense a full or empty bucket. This load cell will provide a signal to the DCS for use in the loading/unloading sequence. Each bucket will also have means to measure internal temperature. These analog signals will be provided to the DCS for monitoring.

Throughout the bucket travel, two travel speeds will be used. From a stationary position, the bucket will start the ascent at a slow travel speed. When the bucket reaches a particular point in its travel speed will be used. The fast travel speed will be used for most of the ascent. Near the top, the slow travel speed will be used, until the bucket is finally stopped at the top.

Sorbent Make-up will be accomplished by a once-per-day sorbent flow from the make-up silo to the regenerator fines separator, by means of gravity feeding.

\section{STATUS}

The hot gas cleanup system described above is the configuration that is intended for the CWL\&P project.

The particulate removal system selected will have a major effect on the performance of the desulfurization system. The performance of the particulate removal system is really governed by the requirements of the gasifier. It is important to remove essentially $100 \%$ of the particulate and recycle it back to the gasifier to achieve 
optimum performance. The system selected is supposed to achieve $99.9 \%$ particulate removal. There are several possibilities for the final particulate removal device including Nextel woven ceramic bags or ceramic candle filters. At this time it appears that ceramic bags will be the selected device.

With any of the possible selections, however, there is the possibility that upset conditions will occur. The conditions that may occur include a bag rupture or a candle filter breaking. These conditions will allow a small amount of dust to go into the hot gas cleanup system. How small the amount is has not been determined. The hot gas cleanup system should be able to handle these conditions. The absorber will act as a packed bed filter for any particulate carryover. The adverse effect on the hot gas cleanup system will include, to some varying degree, the possibility that the fines will clog up the absorption of sulfur in the absorber and require more sorbent make-up, the carbon in the fines will be oxidized in the regenerator causing local hot spots, the oxidized carbon will require more air and more cooling in the heat exchangers. These conditions are not considered normal operating conditions but will be considered in the design of the hot gas cleanup system.

The other major issue with the hot gas cleanup system is the status of the desulfurization technology.

General Electric Environmental Services, Inc. (GEESI) is currently performing work under U. S. DOE Contract No. DE-AC21-87MC23170, "Integrated Operation of a Pressurized Fixed Bed Gasifier and Hot Gas Desulfurization Systerı" which has resulted in extensive test operation of a novel, moving bed, hot gas desulfurization system utilizing a regenerable metal oxide sorbent. Approximately 450 hours of integrated test operation have been achieved, to date, during completion of the first four of six Long Duration Tests contained in the current project's scope.

Testing done to date has been with zinc ferrite material and, more recently, zinc titanate. When these materials have been adequately regenerated, process operation has consistently demonstrated outlet $\mathrm{H}_{2} \mathrm{~S}$ levels of from 0 to $30 \mathrm{ppmv}$ with absorber pressure drop and inlet sulfur loading within the design values. The primary difficulty with system operation has been with the regeneration system, the major issue being creation and preservation of the required temperature levels throughout the sorbent being regenerated. It is desirable to maintain sorbent temperatures between $1200^{\circ}$ and $1500^{\circ} \mathrm{F}$ in the regenerator in order to avoid sorbent sintering at high temperature. Since the recycle system's oxidant diluent is $\mathrm{SO}_{2}$ from the regeneration off-gas, sorbent resident in the regenerator at a temperature of less than $1200^{\circ} \mathrm{F}$ will form zinc sulfate with two undesirable effects: first, sorbent which has been converted to sulfate is unavailable for subsequent removal of $\mathrm{H}_{2} \mathrm{~S}$ in the absorber and second, extensive and repeated sulfation of the material causes mechanical damage and rapid attrition due to the volumetric change associated with sulfurate formation. 
It has also been identified that halogen compounds (particularly chlorine) are transported to the regenerator loop from the coal gas where they result in deposits on heat exchanger surfaces, ultimately severely degrading system performance. Thus, it is necessary to develop a system for the removal of chlorides from the coal gas prior to entering the absorber. Laboratory testing has demonstrated that sodium bicarbonate will remove chlorides from high temperature coal gas. Therefore, a sodium bicarbonate chloride removal system will be provided to circumvent this problem.

During the past year, Long Duration Tests $3,3 a$ and 4 were conducted. Long Duration Test 3 represented the first test operation with zinc titanate and resulted in the expected low leveis of sulfur species in the clean fuel gas, provided that properly regenerated material was returned to the absorber. However, significant difficulty occurred with regenerator operation causing regeneration of the sorbent to be incomplete during portions of the test. In addition, large agglomerates were formed in the regenerator, partially blocking the flow of sorbent regeneration. Although subsequent testing and diagnosis determined the probable cause for the agglomerates, and subsequent off line regenerator operation indicated that the agglomeration is specific to initial operation with new sorbent, it was necessary to modify the regenerator's internal geometry to further enhance gas/solids contact and provide significantly better temperature and oxygen diagnostics. Long Duration Test $3 \mathrm{~A}$ demonstrated the apparent success of these modifications with system operation on anthracite coal in an attempt to minimize chloride carryover into the regenerator prior to incorporation of a $\mathrm{NaHCO}_{3}$ based halogen removal system. However, the anthracite provided a low sulfur level $(0.5 \%)$, as well, and also proved difficult to run at high gasifier throughput due to extensive fines carryover. This latter feature, along with additional cold weather operating problems, limited the absorber and gas turbine simulator operation during the test.

The major result from Long Duration Test $3 A$ was achievement of an understanding of regenerator and resulting temperature distribution in the regenerator and resulting good regenerator performance. This was accomplished in spite of the low levels of sulfide material available. A second result from the test was the reduction in chloride concentration in the recycle system by a factor of from 2 to 3 and an extension of the operating period between recycle system filter cleaning by a similar factor. Post test examination showed a significant reduction in sulfate deposits in the heat exchangers in the recycle loop. Finally, it was possible to operate the turbine simulator for a total of 47 hours, even with extensive particulate carryover due to the operation on anthracite.

During Long Duration Test 4, integrated operation of the gasifier, HGCU, and MS6000 turbine simulator was performed. The system was operated initially on Illinois 6 bituminous, nominal $1.5 \%$ sulfur, to establish baseline performance, then switched to Crown II bituminous, nominal $3.9 \%$ sulfur, to evaluate HGCU operation on high 
sulfur coal, before being switched back to Illinois 6 prior to shutdown on anthracite. Total test duration was 114 hours, of which 55 hours represented fully integrated operation of the gasifier and cleanup.

Near continuous operation of sorbent movement through the regenerator was practiced, with batch transfer rates through the absorber dictated by sulfur concentration in the fuel gas and the desire to maintain $10 \%$ sulfur loading in the sorbent. While operating on Illinois 6 was successful, the high sorbent transfer rates and air requirements for high sulfur Crown II resulted in regeneration lagging absorption and subsequent bypassing of the absorber to allow regeneration to recover.

Sodium bicarboriate injection with the coal feed was used in Test 4 for the first time to remove halogen species from the fuel gas prior to the absorber. While the injection hardware worked flawlessly, the percent chloride removal from the fuel gas was minimal, suggesting that the sodium bicarbonate was tying up with the coal and going down through the gasifier rather than being released in the gas stream. The lack of chloride removal resulted in eventual deposition of zinc sulfate in the recycle loop heat exchangers and required two down periods for cleanout of deposits to restore recycle flow.

The new regenerator temperature control scheme using a scanned maximum temperature to digitally control air input to the second stage resulted in the best temperature control to date in the regenerator, providing spatially uniform temperature profiles with no high temperature excursions. Continued modification to the sorbent transfer valves have also resulted in significant improvement in operability and reliability.

Two Long Duration Tests (5 and 6) remain to be accomplished under the existing contract scope.

Long Duration Test 5 is planned to be conducted utilizing the baseline Illinois 6 coal, zinc titanate, and a modified regenerator to enable two-stage regeneration, thereby providing more effective delivery of oxygen to the sulfided sorbent within the regenerator. The primary emphasis will be on testing the effectiveness of the pressurized sodium bicarbonate injection system for in duct halogen removal.

Long Duration Test 6 is planned to be conducted following the successful completion of Long Duration Test 5. The primary ernphasis of this test will be the evaluation of an alternative sorbent ( $Z$-Sorb). Among the characterizations of the sorbent to be studied are: effectiveness in desulfurization, ability to regenerate, temperature control in the regenerator, and attrition rate. The pressurized sodium bicarbonate system for halogen removal and, if necessary, a guard bed for halogen removal in the regenerator loop, will be tested. 


\section{CONCERNS}

With the need for a reliable gas clean up system, to allow operation of the gasifier, there are a number of concerns with the status of the GEESI system at this time. As described above, some of these concerns are being addressed by GEESI's test program. Below are the concerns regarding the GEESI system:

1. Lack of long operating times - Due to the design of the test program, the longest runs have been around 100 hours. The concern is whether the system can operate for extended periods of time. If the system can not operate continuously, thought should be given to allowing funds for modification or evaluating using another method.

2. GEESI is continuing to test the system in order to understand the proper operation of the regenerator for continuous regeneration. The major concern of failing to operate in a continuous mode is that failure of the clean-up system to capture the sulfur will cause the shutdown of the gasifier. Also, the sulfuric acid plant requires a uniform concentration of $\mathrm{SO}_{2}$ gas. The sulfuric acid plant, as currently designed, can handle a $10-15 \%$ swing in $\mathrm{SO}_{2}$ concentrations over a two hour span. This is a requirement imposed by the supplier of the sulfuric acid plant, Monsanto. With a varying concentration of $\mathrm{SO}_{2}$ in the discharge gas of the regenerator, the acid plant may not be able to accept the variations. If the regeneration of the sorbent can not provide an even flow of gas, the sulfuric acid plant vendor must be made aware of the fluctuation so is to design his plant to accept them if possible. If the sulfuric plant could not handle the swings there may be the need to see if an end product of elemental sulfur is possible.

3. Concern for control of sorbent regeneration - GEESI is currently testing to learn how to control the regeneration of the sorbent. As discussed above, it is desirable to maintain the regenerator in the temperature range of 1200 to 1500 deg. F. Too high a temperature will cause the sorbent to sinter. Too low a temperature will cause the sorbent to form zinc sulfate. The sorbent which is converted to sulfate will be unavailable to remove sulfur in the absorber, and mechanical damage of the sorbent pellets is caused by repeated sulfation. Control of the temperature in the regenerator is crucial to avoid these problems. GEESI is testing a new temperature control method to resolve these issues.

If the sorbent can not be consistently regenerated to $100 \%$ capacity, the rate of sorbent usage will increase. This will also have an effect on the sulfuric acid plant. If the control of sorbent regeneration is not consistent, the unit would probably still operate but the operating cost would increase. 
For concerns $1,2, \& 3 \mathrm{GEESI}$, at DOE's request, is currently proposing to conduct two additional Long Duration Tests of 200 hours each in order to demonstrate the durability of the sorbent through multiple and continuous regeneration cycles. This work is targeted for 1994.

In the current configuration, the regeneration of material is almost continuous. Rotary feeders move sorbent through the regenerator frequently between the "batch" movements of material.

4. GEESI is currently preparing to install a system in their test unit to obtain operating data for a Nahcolite (sodium bicarbonate, $\mathrm{NaHCO}_{3}$ ) system. Information from the testing will provide data on collection of the chlorides and see if there is any physical changes to the Nahcolite. GEESI is intending to test a chloride removal system through pressurized injection of sodium bicarbonate into the gas stream and, if necessary, via a guard bed of sorbent material in the recycle stream.

With the addition of the sodium bicarbonate system, there are added waste streams that must be accounted for. These streams will have to be considered with the other waste streams from the plant. In addition, there is increased equipment capital and operating cost.

5. There is concern with the effect carbon fines have on the control of regeneration. From tests at the pilot plant, there is evidence that when fines are introduced to the regenerator, control of sorbent regeneration can become unstable. This is due to the carbon in the fines competing for the oxygen used for regeneration. When the carbon ignites, local temperature excursions are encountered causing loss of control on the generation of $\mathrm{SO}_{2}$ and possible sintering and agglomeration of the sorbent. If this happens too often during gasifier operation, the system will exceed emission compliance because the sorbent has not been fully regenerated. This should not be a problem during normal operation due to the use of a high temperature filter up steam of the clean-up system. If there is a bag failure, there will be some carbon fines entering the system. The system will have to be designed to accommodate some amount of carryover during these hopefully infrequent upset conditions.

\section{CONCLUSIONS}

The ability of the hot gas system to remove sulfur from the product gas has been proven to be successful. However, due to limited continuous operating times and the inability to control the regeneration of the sorbent in a continuous mode, further testing is required to understand the operating characteristics of the system. 
Additional testing is also required to further develop the design of the components in the system. Development of valves has taken place but there is still work required on the regenerator for scaling up. GEESI is currently addressing these issues in the current test program at its test facility. It appears that all of the above concerns can be addressed satisfactorily to provide a system that can be used in the power generating industry.

At the present time the only clean-up system incorporated in the CWL\&P gasifier unit is the GEESI system. With the understanding that the hot gas clean-up system still requires refinement, startup and operation may require some equipment or operational changes. During the next (third) budget period, experience obtained from operating the test unit as well as slipsteam units on other gasifier projects should provide the necessary data to insure proper operation when the CWL\&P unit is ready to start up.

As an alternative to the GEESI system, other methods for cleaning the gas should be evaluated both for operating and capital cost, and dependability. This would provide a backup alternative if required. During the third budget period, the following areas should be addressed in reviewing alternative gas clean-up methods; 1) effect on scope changes, 2) change in required real estate, 3) effects on current licensing, and 4) cost of associated change out. 



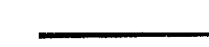

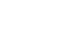

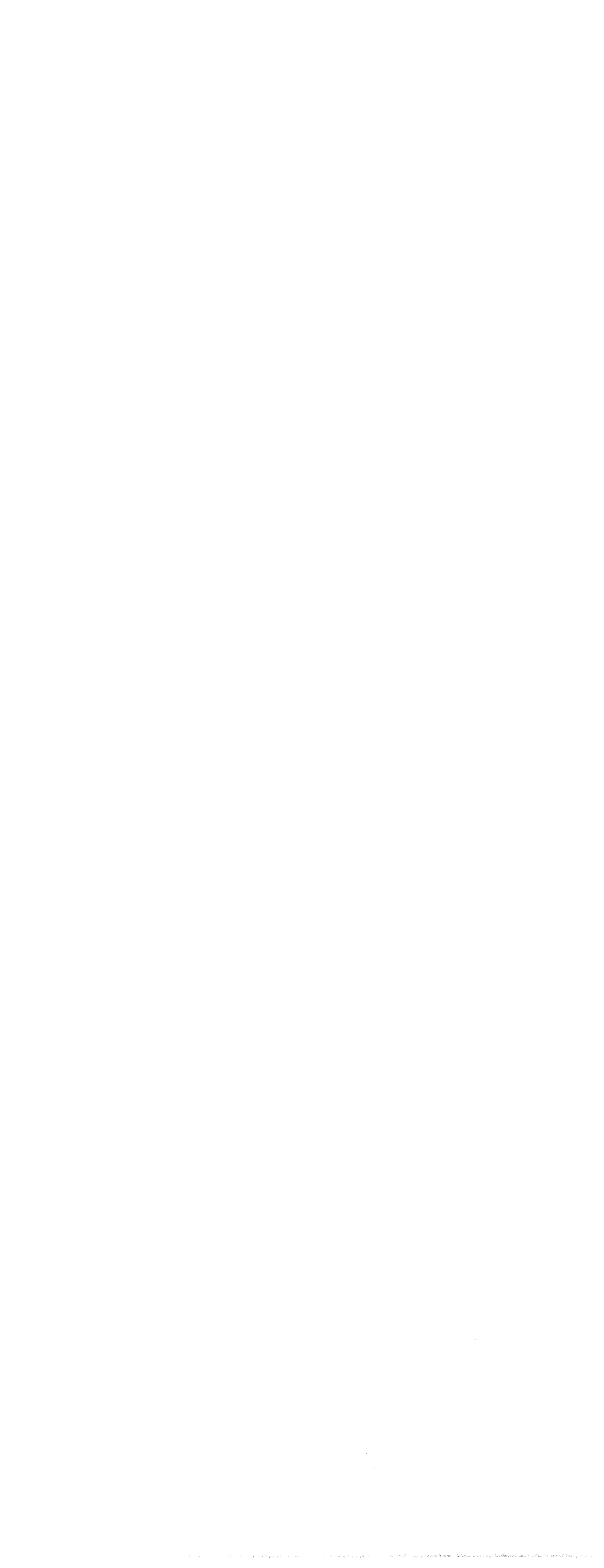

